\title{
Expression of cell cycle proteins in male breast carcinoma
}

\author{
Rani Kanthan ${ }^{1 *}$, Isabella Fried ${ }^{2}$, Theresa Rueckl², Jenna-Lynn Senger ${ }^{1}$, Selliah Chandra Kanthan ${ }^{3}$
}

\begin{abstract}
Introduction: Male breast cancer (MBC) is a rare, yet potentially aggressive disease. Although literature regarding female breast cancer (FBC) is extensive, little is known about the etiopathogenesis of male breast cancer. Studies from our laboratory show that MBCs have a distinct immunophenotypic profile, suggesting that the etiopathogenesis of $\mathrm{MBC}$ is different from FBCs. The aim of this study was to evaluate and correlate the immunohistochemical expression of cell cycle proteins in male breast carcinoma to significant clinico-biological endpoints.

Methods: 75 cases of MBC were identified using the records of the Saskatchewan Cancer Agency over 26 years (1970-1996). Cases were reviewed and analyzed for the immunohistochemical expression of PCNA, Ki67, p27, p16, p57, p21, cyclin-D1 and c-myc and correlated to clinico-biological endpoints of tumor size, node status, stage of the disease, and disease free survival (DFS).

Results: Decreased DFS was observed in the majority of tumors that overexpressed PCNA (98\%, $p=0.004)$. The overexpression of PCNA was inversely correlated to the expression of Ki67 which was predominantly negative (78.3\%). Cyclin D1 was overexpressed in $83.7 \%$ of cases. Cyclin D1 positive tumors were smaller than $2 \mathrm{~cm}(55.6 \%$, $p=0.005)$, had a low incidence of lymph node metastasis $(38.2 \%, p=0.04)$ and were associated with increased DFS of $>150$ months $(p=0.04)$. Overexpression of $c-m y c(90 \%)$ was linked with a higher incidence of node negativity $(58.3 \%, p=0.006)$ and increased DFS $(p=0.04)$. p27 over expression was associated with decreased lymph node metastasis $(p=0.04)$. P21 and p57 positive tumors were related to decreased DFS $(p=0.04)$. Though p16 was overexpressed in 76.6\%, this did not reach statistical significance with DFS $(p=0.06)$ or nodal status $(p=$ 0.07).

Conclusion: Aberrant cell cycle protein expression supports our view that these are important pathways involved in the etiopathogenesis of MBC. Tumors with overexpression of Cyclin D1 and c-myc had better outcomes, in contrast to tumors with overexpression of p21, p57, and PCNA with significantly worse outcomes. P27 appears to be a predictive marker for lymph nodal status. Such observation strongly suggests that dysregulation of cell cycle proteins may play a unique role in the initiation and progression of disease in male breast cancer. Such findings open up new avenues for the treatment of MBC as a suitable candidate for novel CDK-based anticancer therapies in the future.
\end{abstract}

\section{Introduction}

Male breast cancer $(\mathrm{MBC})$ remains a rare yet potentially fatal disease, accounting for less than $1 \%$ of mammary neoplasia [1-4] and $0.17 \%$ of all tumors in men [5], yet this number is rising $[2,6,7]$. While the incidences of $\mathrm{MBC}$ in North America and Western Europe remain low, the proportion of MBC cases is as high as $15 \%$ in

\footnotetext{
* Correspondence: rani.kanthan@saskatoonhealthregion.ca 'Department of Pathology and Laboratory Sciences, Royal University Hospital, Saskatoon, SK, Canada
}

sub-Saharan Africa [6]. The majority of the baseline knowledge and treatment protocols of male breast cancers are largely extrapolated from the treatment and behavior of female breast cancers (FBC) $[1,7]$ as MBC behaves similarly to $\mathrm{FBC}$ in post-menopausal women [8]. The prevalence of $M B C$ increases with age and the presentation occurs at an average age of 60 years, a decade later than in females. The majority of patients present with a painless, firm subareolar mass, tumors usually larger than $2 \mathrm{~cm}$ in diameter, and there may be 
fixation to skin. Pathologically, invasive ductal carcinoma $(93.7 \%)$ is the predominant subtype, and lobular carcinoma is rare $(1.8 \%)$ [5,9]. Nevertheless invasive ductal carcinoma of $\mathrm{MBC}$ is distinctly different from that in females in both presentation and immunophenotype [10]. Risk factors of MBC include testicular disease, benign breast conditions, age, Jewish ancestry, family history, liver disease, obesity, electromagnetic field radiation, infertility, and the strongest association being Klinefelters syndrome $[7,11]$.

Due to the rarity of $\mathrm{MBC}$, limited information is available $[1,3]$. Typically men with breast cancer have a longer duration of symptoms than women [12]. With a lack of awareness and the advanced stage at presentation, such delay in diagnosis often causes a worse prognosis than FBC [13]. Consequently MBC patients have a mortality of $5-10$ years in $36-75 \%$ of cases [13]. Because of uninformed population, the need to implement means of communication to notify males and urge imaging studies is greatly important as a means to lower the risk of worse prognosis in $\mathrm{MBC}$ [5]. This risk is further amplified as men with breast cancer have a significantly higher risk for a secondary malignancy in comparison with the general population [13].

Studies in our laboratory confirm that male breast cancers display distinct immunophenotypic differences in comparison to female breast cancers [1]. The male breast cancers despite being high-grade neoplasms remain estrogen and progesterone receptor positive and cerbB2 and p53 negative [1]. Thus, it is postulated that alternative pathways of carcinogenesis are involved in the development and progression of male breast cancers [1]. Such pathways may implicate cell cycle dysregulation, apoptosis, growth factor pathway and/or androgen receptor pathway [1]. Deregulation of cell cycle control is central to our understanding of the development and progression of all human malignancies [14]. These proteins that play key roles [15-18] in the cell cycle regulation have therefore been the interest of our current study. We investigated the expression of CyclinD1, PCNA, c-myc, Ki67, p21, p27, p57, p16 and correlated the expression level of these factors with clinicopathological factors, such as lymph node status, tumor size, stage of the disease and disease free survival, as in many female breast cancer studies these four clinico-pathological parameters have proven to be of high prognostic value $[16,18]$. Additionally, we compared the outcomes of our study with results, found in the published literature about female breast cancer, to see if there are any major trends, which are unique to male breast cancer. The overall goal of this study was to fill major gaps in knowledge regarding the role of the cell cycle proteins in the etiopathogenesis of male breast cancer. This study is an extension of our established work on immunophenotypic characterization and angiogenesis in male breast cancer in Saskatchewan $[1,10]$.

\section{Materials and methods}

Seventy-five cases of primary male breast cancers were identified using the records of the Saskatchewan Cancer Agency over a period of 26 years (1970-1996). The clinicopathological profiles of these cases are identical to the previous published data from our laboratory [Additional file 1]. 59 of these cases had formalin fixed, paraffin embedded tissue blocks available for the purposes of this study. All cases were reviewed and graded according to Bloom-Richardson criteria for female breast cancers on a routine hematoxylin-eosin-stained slide.

Immunohistochemical studies were performed on a representative deparaffinized tissue section by the avidin-biotin-peroxidase $(A B C)$ technique after antigen retrieval using appropriate positive and negative controls in all cases. Negative controls were obtained by omission of the primary antibody from the staining procedure. The antibodies used with their sources and dilutions are listed in Table 1. The immunohistochemical expression of PCNA, Ki67, p27, p16, p57, p21, cyclin-D1 and c-myc were analyzed on a semi-quantitative basis. As seen in figure 1, each slide was rated on a four-point scale: 0 , no stain (up to $10 \%$ positive cells); 1 , light (11-25\% positive cells); 2 , moderate $(26-50 \%$ positive cells); 3 , heavy (51-75\% positive cells); 4 , intense stain (76-100\% positive cells). The cells were considered positive when more than $10 \%$ of them were stained with the respective antibodies.

Statistical analysis using the Statistical Package for the Social Sciences (SPSS) version 16 compared the immunohistochemical expression of these proteins to the following prognostic clinico-biological parameters: a) nodal status (Figure 2), b) stage of the disease (Figure 3), c) of tumor size (Figure 4), and d) disease free survival (Figure 5). Disease free survival (DFS) was defined as the interval between primary treatment to the first recurrence or death. Statistical significance of the

Table 1 Antibodies examined in this study.

\begin{tabular}{llll}
\hline ANTIBODY & CLONE & DILUTION & SOURCE \\
\hline PCNA & PC10 & prediluted & Ventana \\
Ki67 & MIB-1 & $1 / 100$ & Immunotech \\
p27 & SX53G8 & $1 / 20$ & Dako \\
p16 & F-12 & $1 / 75$ & Oncogene \\
p57 & $25 B 2$ & $1 / 25$ & Novacastra \\
p21 & EA10 & $1 / 5$ & Oncogene \\
cyclin-D1 & P2D11F11 & prediluted & Ventana \\
c-myc & 9E11 & $1 / 200$ & Novacastra \\
\hline
\end{tabular}

This table lists the antibodies used in this study with clone, dilution ratio, and source. 


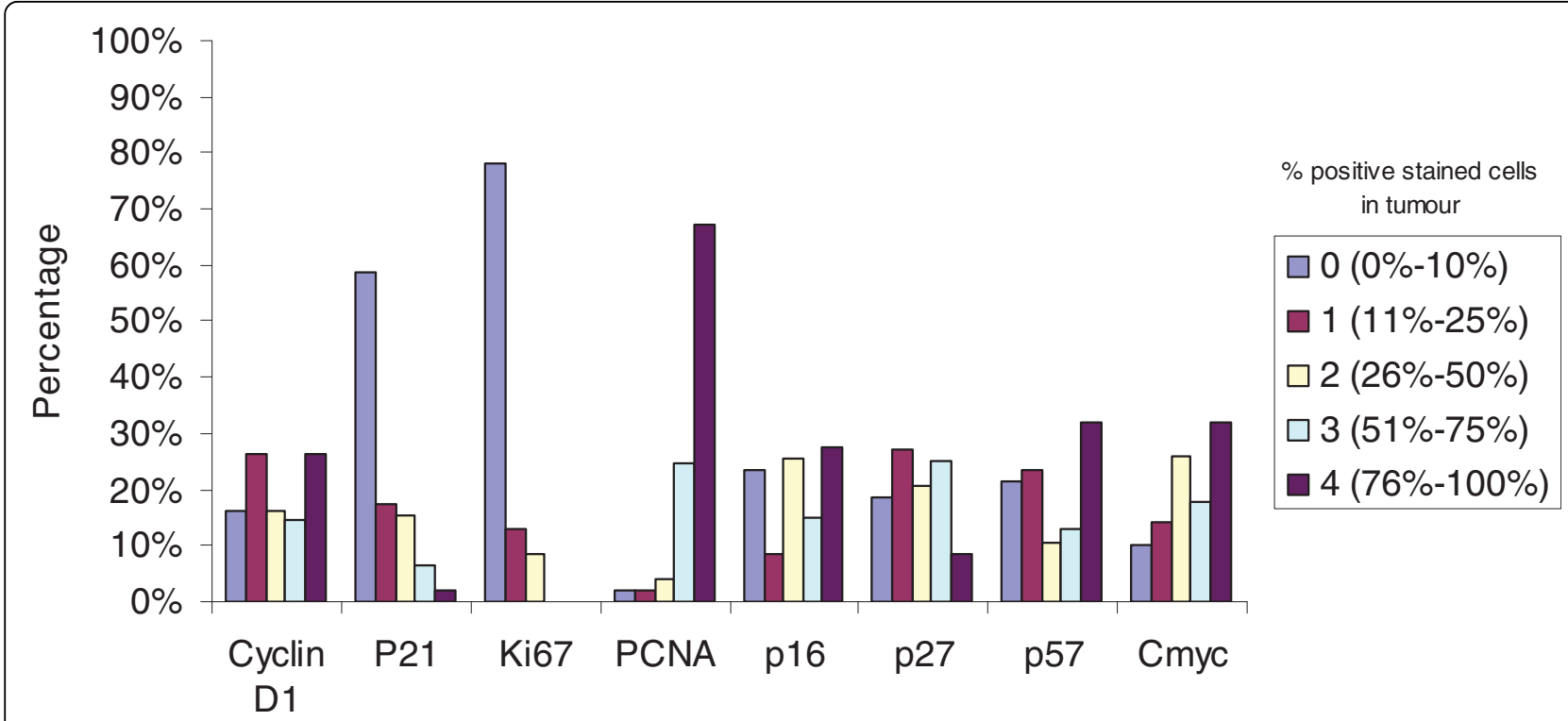

\section{Cell Cycle Proteins}

Figure 1 Percentage of Cell cycle protein expression in the tumor cells. X-axis displays: the expression of the cell cycle proteins CyclinD1, p21, Ki67, PCNA, p16, p27, p57, and c-myc. Y-axis displays: the percentage of positive stained cells in the tumor, where: $0=$ no stain, up to $10 \%$ positive cells. 1 = light stain, $11-25 \%$ positive cells. $2=$ moderate stain, $26-50 \%$ positive cells. $3=$ heavy stain $51-75 \%$ positive cells. $4=$ intense stain $76-100 \%$ positive cells.

immunohistochemical scores were calculated using the Fisher's exact test. Statistical significance of the differences between the cases demonstrating positive and negative cell cycle protein expression in each of the clinicobiological parameter assessed was calculated using the two sample Student'st-test. A P-value of less than 0.05 was considered statistically significant.

This study was conducted with ethics approval from the University of Saskatchewan Advisory Committee on Human Experimentation.

\section{Results and discussion}

Management protocols for male breast cancer patients have been modeled on traditional female breast cancer treatment regimes. However, it is becoming more apparent with increased work in this area that the male breast cancers do not seem to behave similar to female breast cancers. Study of male breast cancers in our own laboratory has revealed that despite the majority of these neoplasms being high-grade cancers, they retain the expression of estrogen and progesterone receptor antibodies and are also less likely to over express Erb-B2 and/or p53 in contrast to high grade female breast cancers. This therefore surmises that the current pathways of treatment protocols applicable in women that are directly linked to ER up-regulation leading to activation of downstream targets such as p53 and/or Erb-B2 does not hold validity in the case of male breast cancers.
Thus, alternative pathways such as cell cycle dysregulation or androgen receptor alterations are perhaps involved in the development and evolution of male breast cancer. As deregulation of cell cycle control is central to our understanding of the development and progression of all human malignancies [14], this was explored in our laboratory in this study protocol.

\section{Cell Cycle}

The cell cycle is a defined set of phases and checkpoints through which a proliferating cell must pass prior to division. As illustrated in figure 6 the four phases are gap $1\left(G_{1}\right)$, synthesis $(S)$, mitosis $(M)$ and gap $2\left(G_{2}\right)$. In the $G_{1}$ phase, the cell grows in preparation for DNA synthesis. It follows therefore that the subsequent phase, the $\mathrm{S}$ phase, is where DNA synthesis occurs. After this, the cell goes through the second gap phase, where the cell grows in preparation for its physical division. This division occurs in the $\mathrm{M}$ phase. After division, the daughter cells may continue proliferating by entering the $G_{1}$ phase; alternatively, the cell may enter a fifth phase labeled $G_{0}$. In $G_{0}$, cells are quiescent (non-dividing); $G_{0}$ cells may experience cessation of proliferation temporarily or in permanence. There are three important checkpoints: $G_{1}, G_{2}$, and metaphase. At the $G_{1}$ checkpoint, mechanisms verify that the cell has grown sufficiently and that the environment is suitable for DNA synthesis. At the $G_{2}$ checkpoint, mechanisms 

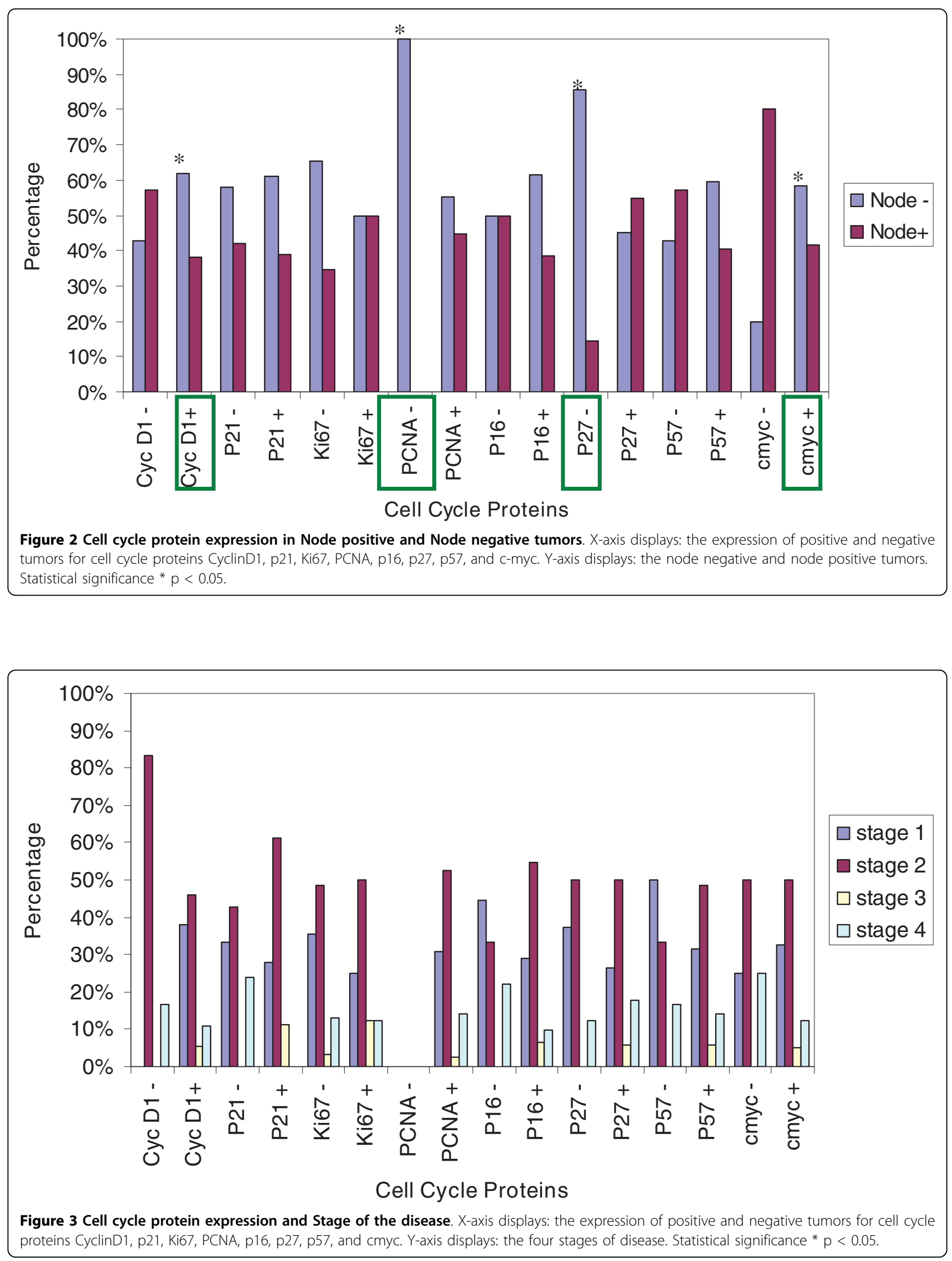


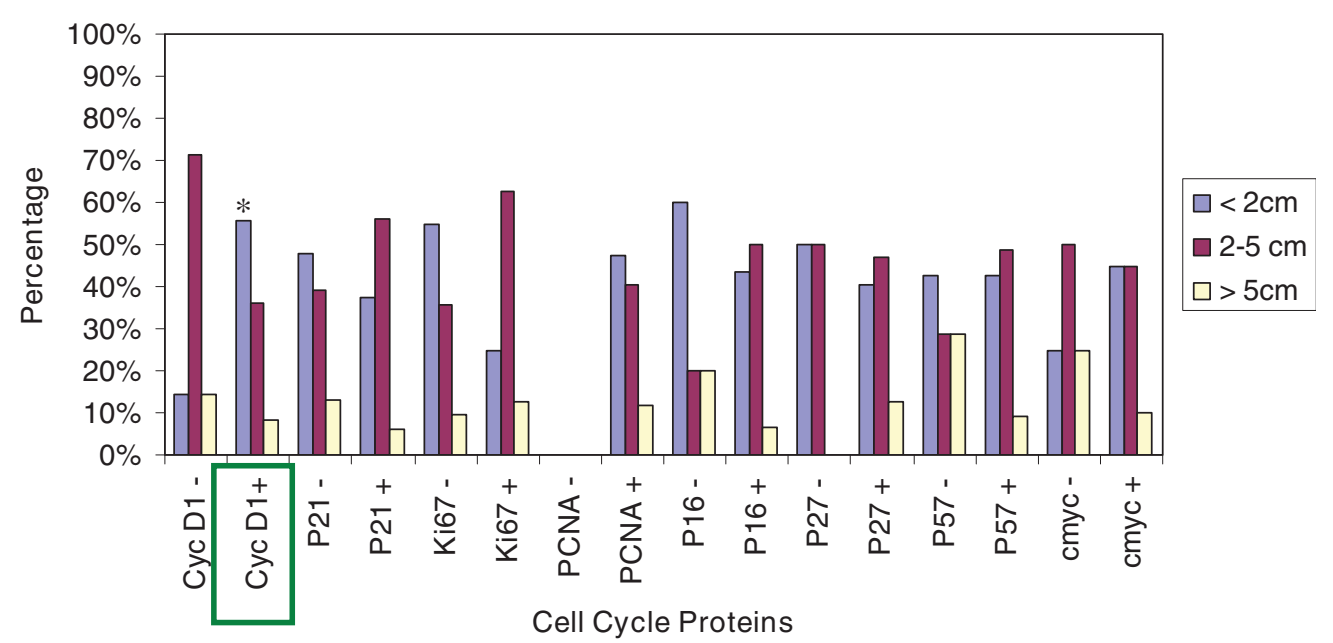

Figure 4 Cell cycle protein expression and Tumor Size. X-axis displays: the expression of positive and negative tumors for cell cycle proteins CyclinD1, p21, Ki67, PCNA, p16, p27, p57, and cmyc. Y-axis: the tumor size data includes: less than $2 \mathrm{~cm}, 2-5 \mathrm{~cm}$, and more than $5 \mathrm{~cm}$. Statistical significance ${ }^{*} p<0.05$.

verify that the DNA has successfully replicated, that the cell is big enough and that the environment is suitable for actual cell division. The metaphase checkpoint verifies that the chromosomes are aligned on the spindle during mitosis. If these conditions cannot be satisfied at their respective checkpoints, there is cessation of the cell cycle. Cells regulate growth through complex signaling pathways that act to maintain and integrate sequence of DNA replication (DNA synthesis, S-phase) that precedes mitosis in the cell cycle. Cyclin-dependent kinase enzymes (CDKs) determine cell cycle proliferation, such that their activation depends on an association with a phase specific protein. DNA damage activation of "checkpoints" ensure genomic integrity through inhibition of CDKs to effect a cell cycle arrest and repair prior to replication (G1 checkpoint), or

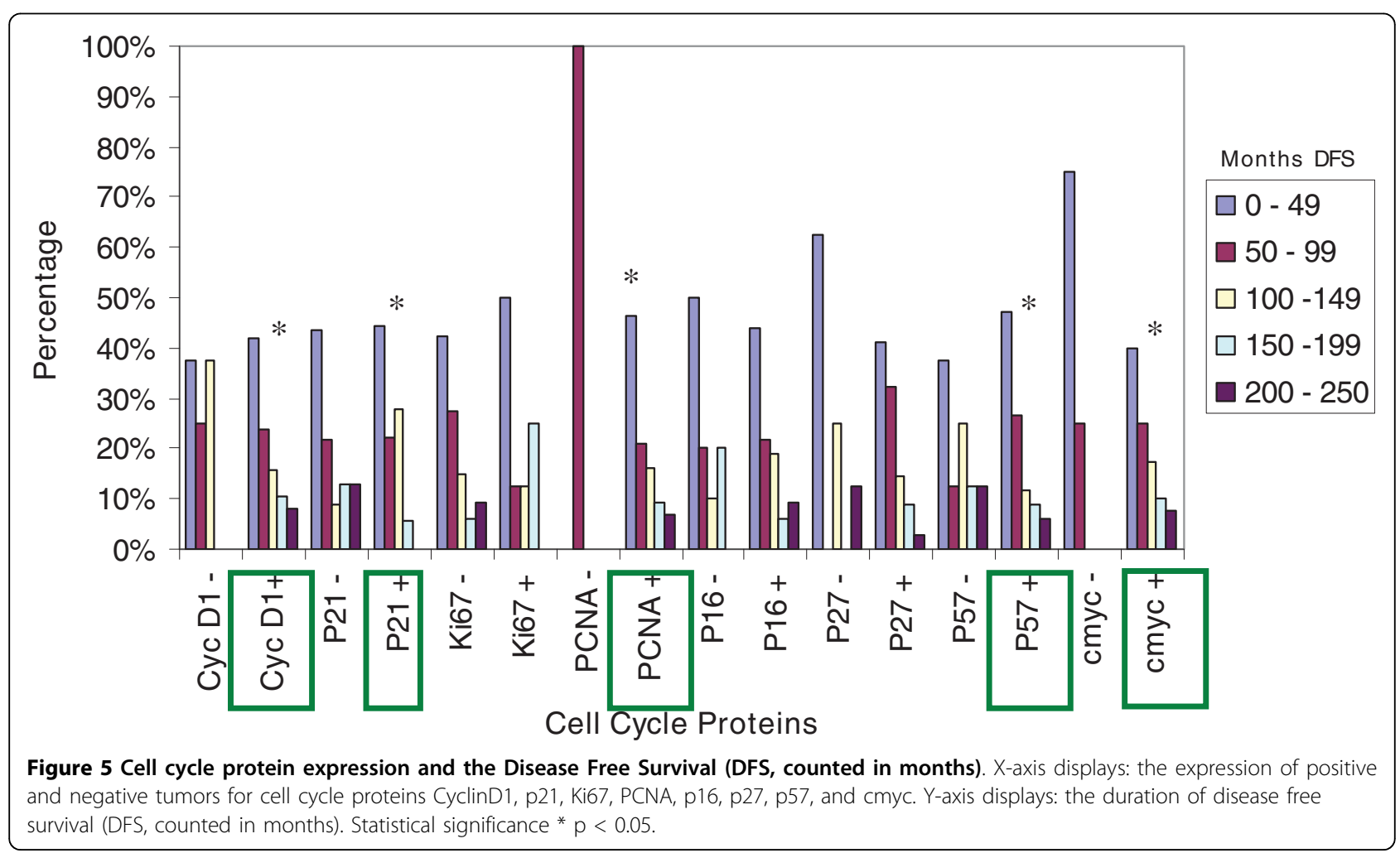


mitosis (G2 checkpoint), with apoptosis constituting an alternative pathway of eliminating DNA damaged cells. Loss of "checkpoint functions" is a hallmark of many human cancers where there is replication and segregation of damaged DNA. P21 functions as a universal cyclin-dependent kinase inhibitory protein (CDK1) with an affinity for G1 and G2 cyclin-CDK complexes, thus acting as "checkpoint proteins" at the G1 and G2 levels (figure 6).

The molecular machinery which controls the cell cycle relies on a delicate balance between factors supporting growth and factors supporting stasis. The growth (or lack thereof) we observe by an individual cell is a reflection of the net sum of all growth promoting and inhibiting factors in its local environment. The factors of interest in this study are cyclin-D1, PCNA, Ki67, p16, p21, p27, p57 and c-myc.

\section{Cyclin-D1}

Cyclins are responsible for controlling entry and progression through the cell cycle, specifically regulating the G1-S phase transition (figure 6). Induction of this cyclin shortens the G1 phase and consequently increases the number of cells passing through this checkpoint $[19,20]$. These proteins complex with (and thus activate) cyclin-dependant kinases (CDKs). Varying levels of different cyclins and CDKs are associated with progression through each of the important transitions in the cell cycle, and can be associated to tumor grade [21]. Cyclin D1 acts as one of the most commonly overexpressed oncogenes in breast cancer, found in $30-60 \%$ of primary ductal adenocarcinoma and universally overexpressed in lobular carcinomas [22,23]. The effects exerted by these diverse proteins include: altering activity of enzymes, altering affinity between proteins, altering affinity between protein and DNA, altering the metabolism of proteins. What effect a CDK may have depends not only on the protein itself, but also the environment, and the substrates involved [14,24-27].

Aberrant expression of cyclinD1 protein is a common feature in female breast cancers [24-27]. As a result of alternative splicing of the transcript CCND1, two isoforms of cyclin D1 exist: the conventional cyclin D1a and cyclin D1b [28]. In FBCs while high cyclin D1a levels are not associated with recurrence or metastases, high cyclin D1b levels are associated with poor survival and can predict disease outcomes. High cyclin D1a are found predominantly in ER-positive tumors and are inversely correlated with Ki67 with little impact on disease outcome. In contrast, elevated cyclin D1b expression was independently associated with adverse clinical outcomes including recurrence, distant metastasis and decreased survival thereby identifying a unique subset of tumors associated with increased disease progression [28].
In our study $83.7 \%$ of the cases were positive for cyclin-D1 overexpression (figure 1). Proven by several studies, female breast cancers also show high expression of Cyclin D1 [[14] (28\%), [24](48.3\% >5\%), [25](59\% $>5 \%)$, [27,29] (65\% >5\%), [30] $(66.7 \%>10 \%)$, [31,32]]. Cyclin D1 positive tumors seemed to be less likely associated with lymph node metastasis (38.2\% vs. $57.1 \%$ in cyclin D1 negative tumors at $\mathrm{p}=0.04$, figure 2 ). This is in contrast to studies in female breast cancer that do not find a statistical significant correlation between cyclin D1 and metastatic disease and axillary lymph node involvement $[19,25,29]$, yet there was an association between the expression of cyclin D1b and distant metastasis [28]. There was a strong tendency for cyclin D1 positive male breast tumors to be smaller than $2 \mathrm{~cm}$ $[25,29](55.6 \%$ vs. $14.3 \%$ of cyclin D1 negatives at $\mathrm{p}=$ 0.005 , figure 4 ). Female breast cancers do not seem to have this correlation [25,29]. There was no correlation of CyclinD1 overexpression and the stage of the disease (figure 3). As seen in figure 5, none of the patients having a CyclinD1 negative tumor had a DFS over 150 months, in comparison to $18.4 \%$ in the $\mathrm{CycD} 1$ positive group ( $p=0.04)$. In the published literature this is controversial and inconclusive. In some studies no correlation between CyclinD1 and DFS could be found $[14,19,26]$ while Gillet et al has shown moderate/strong staining for CyclinD1 was associated with improved DFS and overall survival relative to tumors that stained weakly or negatively[32]. Yet negative Cyclin D1 tumors had an adverse prognosis with poor outcomes especially if they were ER negative tumors as well [33]. Our study shows that negative Cyclin D1 tumors are associated with adverse prognosis of increased incidence of lymph node metastasis, larger tumors, and decreased DFS.

\section{PCNA}

Proliferating cell nuclear antigen (PCNA) is a protein which forms a ring around a portion of DNA serving to anchor various DNA replication and repair proteins and regulates proliferation throughout the cell cycle [34-36] (figure 6). PCNA expression was elevated in our study in $98 \%$ of the cases, with $67.4 \%$ showing intensive staining (figure 1). Due to the low percentage of PCNA negative cases, a comparison of the clinicopathological parameters between the positive and negative group was not feasible. This elevated expression of PCNA is also seen in studies on female breast cancers, where $71.4 \%$ $100 \%$ of cases were considered PCNA positive [17,37] Mean proliferating index was $76.1 \%$, with a range from $0-100 \%$. Compared to results in female breast cancer, this value seems to be far above the range of results reported by others $(10.2 \%-28.7 \%)$ [34]. In the female breast cancer literature the correlation between the range of proliferating indexes $[\mathrm{PI}]$ and classical 


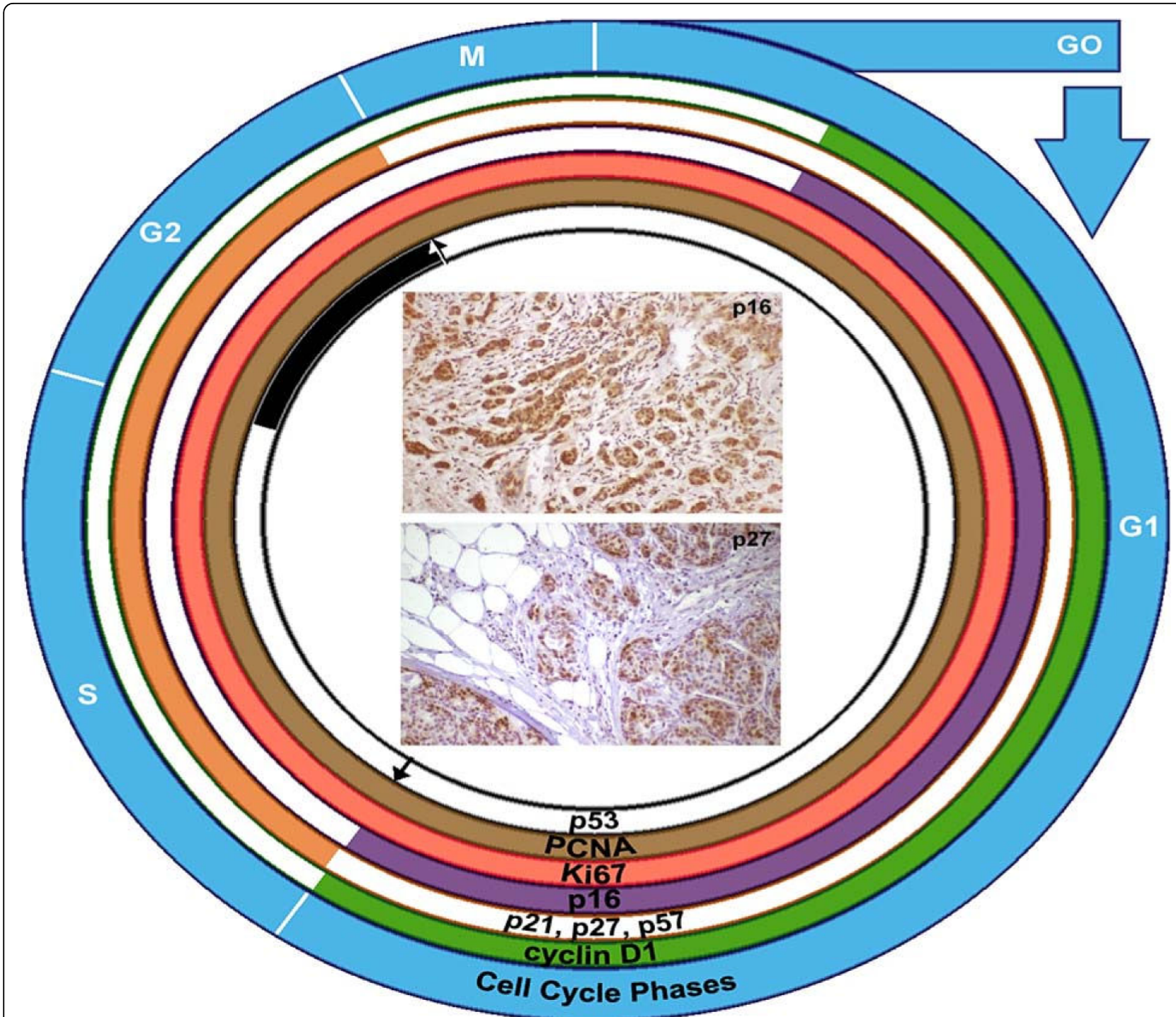

Figure 6 Schematic illustration of the regulatory proteins in the cell cycle phases. The cell cycle is illustrated (outer blue circle) schematically through its various phases $-G_{1} / S, G_{2} / M$. ( $G_{1}=$ growth phase $1 ; S=$ synthesis; $G_{2}=$ growth phase $2 ; M=$ mitosis). The proteins studied are color coded to the most prominent phase of their action in the cell cycle: Cyclin D1 is green, $G_{1}$. p21, p27, p57 are orange, S/G p p16 is violet, $G_{1}$. Ki67 (coral) and PCNA (brown) all phases. P53 is black, checkpoint $G_{2} / M$. The insert are two photomicrographs of the immunohistochemical expression of p27 and p16 in the malignant breast cancer cells at a medium magnification ×150.

prognostic factors such as tumor size and nodal status is controversial. Some authors found strong, statistically significant correlation between PI, PCNA or Ki67 level and tumor size or nodal status [34]. The majority of investigators however, think that such relationship do not exist [34]. In our study in male breast cancer the PCNA was positive in $55.3 \%$ of node negative tumors and $44.7 \%$ of node positive tumors, $\mathrm{p}=0.0001$ (figure 2 ). As far as size of the tumor was concerned no significant statistical significance could be found with $47.6 \%$ positive PCNA expression in tumors with a size less than 2 $\mathrm{cm}$ (figure 4). However, PCNA overexpression was associated with decreased DFS $(98 \%, \mathrm{p}=0.004)$ indicating perhaps disease progression with increased adverse clinical outcome.

\section{C-myc}

The c-myc gene is amplified and/or overexpressed in different frequencies in most human malignancy [38], though amplification occurs more frequently in metastases than in primary tumors [39]. A regulator of a cell's size and participant in cellular functioning such as growth, differentiation, apoptosis, and metabolism [38], this oncogene can both activate and repress specific 
genes [21]. The c-myc protein binds to DNA and activates transcription for many growth related genes (including CDKs). The myc protein is induced when a cell is stimulated to pass from the quiescent $G_{0}$ state to the active $G_{1}$ state. The normal myc gene is a protooncogene, thus, when it becomes dysregulated (mutation or other) it promotes uncontrollable cell division [40]. In our study of male breast cancer, c-myc was expressed in $90 \%$ of the cases (figure 1). Several critical issues regarding the significance of $\mathrm{c}$-myc in human breast cancer still remain obscure. The frequencies of the expression levels vary greatly from one report to another (50-100\%) [40]. In our study the percentage of cases being node negative seemed to be lower in c-myc negative cancers $(20 \%$ vs. $58.3 \%, \mathrm{p}=0.006)$ in $\mathrm{c}$ - $\mathrm{myc}$ positives) as demonstrated in figure 2 .

In a female breast cancer study on node negative tumors done by Schlotter, c-myc amplification appears to represent a prognostic marker to predict early recurrence [41]. Pich et al has reported a 107 month survival for c-myc negative cases and 52 months for c-myc positive male breast cancer patients [42]. As seen in figure 5 , in our study all c-myc negative tumors had a DFS lower than 100 months, with only one living longer than 50 months $(\mathrm{p}=0.04)$. There was no statistically significant association between c-myc protein levels and stage of the disease as seen in figure 3. Though not statistically significant, $\mathrm{p}=0.08,55 \%$ of tumors $>2 \mathrm{cms}$ were c-myc positive in our study (figure 4). Interestingly, Aulmann et al, 2002 using FISH and focusing on DCIS, detected amplification of c-myc in only $20 \%$ of the cases, but found a correlation of c- myc with increased tumor size and proliferation [40]. Further, In FBCs, high $\mathrm{C}$-myc expression levels are correlated on one hand with larger sizes tumors but on the other hand with better survival [38]. Similar parallel trends are seen in our study, wherein c-myc overexpression though associated with larger tumor size, had lower incidence of lymph node metastasis and better DFS indicating a favorable prognosis.

\section{Ki-67}

Ki67 nuclear antigen is associated with cell proliferation and is found throughout the cell cycle except the Go phase [16,35,43](figure 6) and has become recognized as a proliferation marker in breast cancer [44] where a higher percentage correlates with an increase in tumor grade[45]. In our study Ki67 expression was mostly negative $(78.3 \%$, figure 1$)$. This is in contrast to high grade FBC with high Ki67 expression in 95\% of the cases [37]. Within the numbers of tumors considered positive for Ki67 expression, the proliferating index (PI) ranged from $0 \%-40 \%$, leading to a mean PI of $6.6 \%$. The mean PI so falls within the range of values reported by others studying female breast cancers (6\%-22\%) [34,35]. In our study Ki67 negative cases had a higher tendency of being node negative $(65.5 \%$ vs. $50 \%$ in positive cases, figure 2). Furthermore there was a trend of Ki67 negative tumors, having a size less than $2 \mathrm{~cm}$ with $54.8 \%$ of the Ki67 negative tumors being smaller than $2 \mathrm{~cm}$, whereas only $25 \%$ of the Ki67 positives were of similar size. Though not statistically significant, in our study Ki67 positive tumors seemed to be associated with larger tumor size as seen in figure 4. This finding is congruent with literature stating $20-40 \%$ of $\mathrm{MBC}$ cases are positive for $\mathrm{Ki}-67$ and when combine with androgen receptor negativity tend towards worse prognosis [45]. In female breast cancers, some authors found strong, statistically significant correlation between PI, PCNA or Ki67 level and tumor size as well as nodal status [34]. As already mentioned the majority of investigators, think that such relationship does not exist $[16,36,37,43]$. In this study the mean PI node negative male breast tumors was $2.73 \%$ (range $0 \%-10 \%$ ) and $7.7 \%$ (range $0 \%-30 \%$ ) in node positives (figure 2). Tumors with a size less than $2 \mathrm{~cm}$ had an IP of $3.95 \%$ (range $40 \%-100 \%$ ) and those larger than $2 \mathrm{~cm}$ one of $9.3 \%$ (range $0 \%-40 \%$ ). Remarkable is also the inverse correlation between Ki67 and PCNA within the tumors of this study. Also in studies about female breast cancer some authors have found a similar lack of correlation between the two indices [35,36]. Yet there are also studies that report the opposite. No significant correlations were observed between the Ki67 expression levels and tumor stage (figure 3) and DFS as demonstrated in figure 5. In our study, Ki67 does not appear to play a dominant role in disease progression or survival in male breast cancer.

\section{p21, p27, p57, p16}

These proteins are part of the CDKN1A family; a family of proteins which broadly inhibits the activity of CDKs. As illustrated in figure 6 these proteins act as a brake for cell proliferation; their expression contributing to a cessation in the cell cycle, especially during the $\mathrm{S}$ and $\mathrm{G}_{2}$ phases $[15,18,33,46,47]$.

p21 remained negative in $58.7 \%$ of our male breast cancer cases(figure 1). As other studies showed, there was no significant difference in this point concerning the female counterpart [46]. In our study $94.4 \%$ of tumors showing a p21 expression had a DFS shorter than 150 months (vs. $74 \%$ in the negative group, $\mathrm{p}=$ 0.04 ) as seen in figure 5 . This trend of p21 negativity combined with a longer disease free survival in our cases of male breast cancer has also seen in a study of female breast cancer [48]. In another existing study the immunohistochemical expression of p21 was analyzed and compared between 27 cases of primary male breast 
cancer $(\mathrm{MBC})$ and 101 cases of female breast cancer (FBC). A statistically significant difference in the immunostaining of p21 in male patients compared with females was found. Expression of p21Waf1 was observed in 19 of the 27 primary MBC (70.3\%) vs. 29 of $101 \mathrm{FBC}$ (29\%) [47]. André et al has demonstrated the occurrence of p21-positive is significantly higher in MBC than FBC (FBC: $58 \%$ positive $42 \%$ negative vs. MBC: $4 \%$ negative $96 \%$ positive) [49]. This further strengthens the view that $\mathrm{MBC}$ and $\mathrm{FBC}$ probably have distinct tumor oncogenesis. The exact biological role of p21 expression remains unclear as there is no evidence of strong correlation with other cell cycle regulatory proteins or Ki-67 [49]. Yet, overall p21 positivity is associated with adverse outcomes as it is associated with decreased DFS.

p27 is a CDK inhibitor required for entry to S-phase. Loss of p27 is believed to contribute to oncogenesis [47]. Most often associated with cell cycle arrest $[47,50]$, p27 maintains CDKs in an inactive state and thus blocks entry to the S-phase [51] and in tumors with a high estrogen receptor expression and low Sphase fraction has a high expression [47]. The level of p27 is not stagnant: the level rises as the cells exit the cell, proteolysis causes the levels to drop, and can be inactivated by cyclin sequestering [50]. P27 overexpresion in MBC could reflect a failing feedback attempt of a normal protein rather than be the result of an alteration in the p21 gene. Expression of p27 was noted in $81.2 \%$ of our cases (figure 1). A study about the role of p27 in human breast cancer cell lines showed that 5 out of $12(41.7 \%)$ of the tested cell lines showed high level p27 expression [15]. Similar to our findings in Curigliano's study the immunohistochemical expression of p27 was analyzed and compared between 27 cases of primary male breast cancer (MBC) and 101 cases of female breast cancer (FBC). P27 immunoreactivity was detected in 26 of 27 male breast patients (96.2\%) vs. 39 of 101 FBC (39.3\%) [47]. A salient finding in our study is the high percentage $(85.7 \%)$ of node negative cancers in the $\mathrm{p} 27$ negative group in comparison to $45.2 \%$ at $\mathrm{p}=0.04$ (figure 2). P27 expression in node negative cases suggests that p27 may be a predictive marker for lymph nodal status.

Expression of p57 was noted in $78.7 \%$ of our MBC cases (figure 1). P57 positives tumors showed a slightly higher tendency to be associated with node positivity ( $57.1 \%$ vs. $40.6 \%$ of the p57 negative cases, figure 2 ). As for tumor size (figure 4), 28.6\% of the p57 negatives were larger than $5 \mathrm{~cm}$ in comparison to $9.1 \%$ in the p57 positive cases suggesting loss of p57 expression being associated with larger tumor size. Tumors that were p57 and p21 positive were associated with decreased DFS ( $\mathrm{p}=0.04$ ) (Figure 5) indicating adverse outcomes.

\section{P16}

p16 belongs to the CDKN2A family of proteins, another family of CDK inhibitors $[18,52]$. This family of proteins particularly inhibits the activity of active CDK4 and CDK6 [52]; thus, their inhibitory activity occurs primarily in the $G_{1}$ phase where it accumulates and inhibits progression to the S-phase [53] (figure 6). Reduced expression of this protein is caused by its inactivation by deletion, mutation, or methylation [53]. Mechanisms leading to p16 overexpression is however not well understood. As p16 is inactivated in $85 \%$ of tumorderived cells lines, it is classified as a tumour suppressor and is the second most common genetic mutation found in breast cancer [50]. In our study $76.6 \%$ of all tumors showed p16 expression (figure 1). Whereas this finding is not discrepant with another study about the expression of p16 in female breast carcinomas [52], there are other studies where half of the breast cancers in women failed to express p16 $[18,54,55]$. Neither the presence of p16 positive nuclei nor the lack of detectable staining in these studies was statistically significant with tumor size (figure 4), tumor differentiation or nodal status (figure 2). Though the higher percentage of large tumors $>5 \mathrm{cms}$ were associated with loss of p16 expression ( $20 \%$ vs. $6.7 \%$ in the positives) we could not find any statistical correlation between the expression of $\mathrm{p} 16$ and the DFS ( $\mathrm{p}=0.06$ ) (figure 5), nodal status ( $\mathrm{p}=$ 0.07 ) (figure 2) or the stage of the disease as demonstrated in figure 3 . Thus similar to other investigators despite aberrant expression, the significance of the expression of P16 in male breast cancer could not be established $[52,53,55]$.

\section{Conclusion}

Male breast cancer is a rare yet potentially aggressive disease with a distinctive immunophenotype with alternative pathway for tumor oncogenesis distinct from female breast cancer. The management of MBC therefore necessitates different treatment regimes rather than the traditional FBC approaches. Our study confirms aberrant expression of cell cycle proteins in male breast cancers. Tumor cells with overexpression of Cyclin D1 and c-myc are associated with favorable outcomes while overexpression of p21, p57, and PCNA are linked with adverse outcomes. P27 appears to be a predictive marker for lymph nodal status. The exact role of p16 expression remains undetermined. These cell cycle protein markers may identify a unique subset of tumors that may be associated with aggressive disease. Dysregulation of cell cycle proteins may play a unique role in the initiation and progression of disease in male breast cancer. This opens up a new perspective for the treatment of $\mathrm{MBC}$ as a suitable candidate for novel CDKbased anticancer therapies in the future. 
Additional file 1: Appendix 1. Table from Archives of Pathology \& Laboratory Medicine: Vol. 127, No. 1, pp. 36-41.

Click here for file

[http://www.biomedcentral.com/content/supplementary/1477-7819-8-10S1.DOC]

\section{Acknowledgements}

The authors wish to thank the Saskatchewan Cancer Agency for their assistance in obtaining the records required for this study and to the Royal University Hospital Foundation Grant that supported the laboratory workup on the cases studied. We would also like to thank Todd Reichert and Michelle Hesson for their help with the illustrations.

\section{Author details}

${ }^{1}$ Department of Pathology and Laboratory Sciences, Royal University Hospital, Saskatoon, SK, Canada. ${ }^{2}$ Department of Dermatology, University of Medicine, Graz Austria. ${ }^{3}$ Department of Surgery, Royal University Hospital, Saskatoon, SK, Canada.

\section{Authors' contributions}

All authors participated in the writing of this manuscript. RK is the corresponding and first author who was involved in the design and implementation of the study with overseeing of the data gathering and data interpretation. IF and TR are international exchange medical students who worked on this project during the summer of their elective here in our laboratory. JLS is an undergraduate summer student who was involved with extensive revisions and writing of this manuscript. SCK is the senior author of this paper.

\section{Competing interests}

The authors declare that they have no competing interests.

Received: 14 September 2009

Accepted: 12 February 2010 Published: 12 February 2010

\section{References}

1. Muir D, Kanthan R, Kanthan SC: Male Versus Female Breast Cancers. A Population-Based Comparative Immunohistochemical Analysis. Archives of Pathology and Laboratory Medicine 2003, 127(1):36-41.

2. Weiss JR, Moysich KB, Swede H: Epidemiology of Male Breast Cancer. Cancer Epidemiology, Biomarkers \& Prevention 2005, 14(1):20-26.

3. Giordano SH, Cohen DS, Buzdar AU, Perkins G, Hortobagyi GN: Breast Carcinoma in Men: a population-based study. Cancer 2004, 101(1):51-57.

4. Giordano SH, Buzdar AU, Hortobagyi GN: Breast Cancer in Men. Annals of Internal Medicine 2002, 137(8):678-687.

5. Bagnera S, Campanino P, Barisone F, Mariscotti G, Gandini G: Imaging, Histology and Hormonal Features of Five Cases of Male Breast Cancer Observed in a Single Year: Comparison with the Literature. Radiological Medicine 2008, 113(8):1096-1109.

6. Nahleh Z, Girnius S: Male Breast Cancer: A Gender Issue. Nature Clinical Practice Oncology 2006, 3(8):428-437.

7. Schaub NP, Maloney N, Schneider H, Feliberti E, Perry R: Changes in Male Breast Cancer Over a 30-Year Period. The American Surgeon 2008, 74(8):707-712.

8. Lanitis S, Rice AJ, Vaughan A, Cathcart P, Filippakis G, Al Mufti R, Hadjiminas DJ: Diagnosis and Management of Male Breast Cancer. World Journal of Surgery 2008, 32(11):2471-2476.

9. Giordano SH: Male Breast Cancer: It's Time for Evidence Instead of Extrapolation. Onkologie 2008, 31(10):505-506.

10. Frangou E, Lawson J, Kanthan R: Angiogenesis in Male Breast Cancer. World Journal of Surgical Oncology 2005, 3(1):16-30.

11. Contractor KB, Kaur K, Rodrigues GS, Kulkarni DM, Singhal H: Male Breast Cancer: Is the Scenario Changing. World Journal of Surgical Oncology 2008 16(6):58-69.

12. Park S, Kim JH, Koo J, Park BW, Lee KS: Clinicopathological Characteristics of Male Breast Cancer. Yonsei Medical Journal 2008, 49(6):978-986.
13. Lee UJ, Jones JS: Incidence of Prostate Cancer in Male Breast Cancer Patients: a Risk Factor for Prostate Cancer Screening. Prostate Cancer and Prostatic Diseases 2009, 12(1):52-56.

14. Mclntosh GG, Anderson JJ, Milton I, Steward M, Parr AH, Thomas MD, Henry JA, Angus B, Lennard TW, Horne $\mathrm{CH}$ : Determination of the prognostic value of cyclin D1 overexpression in breast cancer. Oncogene 1995, 11(5):885-91.

15. Fredersdorf $S$, Burns J, Milne AM, Packham G, Fallis L, Gillett CE, Royds JA, Peston D, Hall PA, Hanby AM, Barnes DM, Shousha S, O'Hare MJ, Lu X: High level expression of p27(kip1) and Cyclin D1 in some human breast cancer cells: inverse correlation between the expression of p27(kip1) and degree of malignancy in human breast cancer and colorectal cancers. Proceedings of the National Academy of Science USA 1997, 94(12):6380-5.

16. Haerslev T, Jacobsen GK, Zedeler K: Correlation of growth fraction by Ki67 and proliferating cell nuclear antigen (PCNA) immunohistochemistry with histopathological parameters and prognosis in primary breast carcinomas. Breast Cancer Research and Treatment 1996, 37(2):101-13.

17. Goel MM, Goel R, Mehrotra A, Nath P, Agarwal PK, Singh K, Mehrotra R: Immunohistochemical localization and correlation of p53 and PCNA expression in breast carcinoma. Indian Journal of Experimental Biology 2000, 38(3):225-230.

18. Emig $R$, Magener A, Ehemann V, Meyer A, Stilgenbauer F, Volkmann M, Wallwiener D, Sinn HP: Aberrant cytoplasmic expression of the p16 protein in breast cancer is associated with accelerated tumour proliferation. British Journal of Cancer 1998, 78(12):1661-8.

19. Turner BC, Gumbs AA, Carter D, Glazer PM, Haffty BG: Cyclin D1 expression and early breast cancer recurrence following lumpectomy and radiation. International Journal of Radiation Oncology Biology Physics 2000, 47(5):1169-76

20. Elsheikh S, Green AR, Aleskandarany MA, Grainge M, Paish CE, Lambros MB, Reis-Filho JS, Ellis IO: CCND1 Amplification and Cyclin D1 Expression in Breast Cancer and their Relation with Proteomic Subgroups and Patient Outcome. Breast Cancer Research and Treatment 2008, 109(2):325-335.

21. Jensen LB, Bartlettt JM, Witton CJ, Kirkegaard T, Brown S, Müller S, Campbell F, Cooke TG, Nielsen KV: Frequent Amplifications and Deletions of $\mathrm{G}_{1} / \mathrm{S}$-phase Transition genes, CCND1 and MYC in Early Breast Cancers: A Potential Role in $G_{1} / S$ Escape. Cancer Biomarkers 2009, 5(1):41-49.

22. Sutherland RL, Musgrove EA: Cyclins and Breast Cancer. Journal of Mammary Gland Biology and Neoplasia 2004, 9(1):95-104.

23. Cho EY, Choi YL, Han JJ, Kim KM, Oh YL: Expression and Amplification of Her2, EGFR and Cyclin D1 in Breast Cancer: Immunohistory and Chromogenic in situ Hybridization. Pathology International 2008, 58(1):17-25

24. Alle KM, Henshall SM, Field AS, Sutherland RL: Cyclin D1 protein is overexpressed in hyperplasia and intraductal carcinoma of the breast. Clinical Cancer Research 1998, 4(4):847-54

25. van Diest PJ, Michalides RJ, Jannink I, Valk van der P, Peterse HL, de Jong JS, Meijer CJ, Baak JP: Cyclin D1 expression in invasive breast cancer. Correlations and prognostic value. American Journal of Pathology 1997, 150(2):705-11.

26. Michalides $R$, Hageman $P$, van Tinteren $H$, Houben $L$, Wientjens $E$, Klompmaker R, Peterse J: A clinicopathological study on overexpression of cyclin D1 and p53 in a series of 248 patients with operable breast cancer. British Journal of Cancer 1996, 73(6):728-34.

27. Zhang SY, Caamano J, Cooper F, Guo X, Klein-Szanto AJ: Immunohistochemistry of cyclin D1 in human breast cancer. American Journal of Clinical Pathology 1994, 102(5):695-8.

28. Millar EK, Dean JL, MCNeil CM, O'Toole SA, Henshall SM, Tran T, Lin J, Quong A, Comstock CE, Witkiewicz A, Musgrove EA, Rui H, Lemarchand L, Setiawan VW, Haiman CA, Knudsen KE, Sutherland RL, Knudsen ES: Cyclin D1b Protein Expression in Breast cancer is Independent of Cyclin D1a and Associated with Poor Disease Outcome. Oncogene 2009, 28(15):1812-1820.

29. Park K, Han S, Kim HY, Ko I: Cytologic evaluation of cyclin D1 expression in primary breast carcinoma. Cancer 2001, 93(3):211-5.

30. Yano M, Naito Z, Yokoyama M, Shiraki Y, Ishiwata T, Inokuchi M, Asano G. Expression of hsp90 and cyclin D1 in human breast cancer. Cancer Letters 1999, 137(1):45-51

31. Saddik M, Lai R, Medeiros LJ, McCourty A, Brynes RK: Differential expression of cyclin D1 in breast papillary carcinomas and benign 
papillomas: an immunohistochemical study. Archives of Pathology and Laboratory Medicine 1999, 123(2):152-6.

32. Gillett C, Smith P, Gregory W, Richards M, Millis R, Peters G, Barnes D: Cyclin D1 and prognosis in human breast cancer. International Journal of Cancer 1996, 69(2):92-9.

33. Tanyi J, Tory K, Bankfalvi A, Shroder W, Rath W, Fuzesi L: Analysis of p53 mutation and cyclin D1 expression in breast tumors. Pathology \& Oncology Research 1999, 5(2):90-4.

34. Markiewski M, Domagala W: Immunohistochemical assessment of proliferation rate of breast carcinoma cells using Ki-67, MIB0-1 and antiPCNA monoclonal antibodies. Polish Journal of Pathology 1996 47(4):189-94

35. Sullivan RP, Mortimer G, Muircheartaigh IO: ell proliferation in breast tumours: analysis of histological parameters Ki67 and PCNA expression. Irish Journal of Medical Sciences 1993, 162(9):343-7.

36. Leonardi E, Girlando S, Serio G, Mauri FA, Perrone G, Scampini S, Dalla Palma P, Barbareschi M: PCNA and Ki67 expression in breast carcinoma: correlations with clinical and biological variables. Journal of Clinical Pathology 1992, 45(5):416-9.

37. Jeziorski A, Blonski JZ, Niewiadomska $H$ : The expression of products of oncogens c-erbB2 and EGFR and proliferation antigens Ki67 and PCNA in primary invasive ductal cancer or female breast. Journal of Experimental \& Clinical Cancer Research 2000, 19(1):61-7.

38. Liao DJ, Dickson RB: C-Myc in Breast Cancer. Endocrine-Related Cancer 2000, 7(3):143-164

39. Mars WM, Saunders GF: Chromosomal Abnormalities in Human Breast Cancer. Cancer and Metastasis Review 1990, 9(1):35-43.

40. Aulmann S, Bentz M, Sinn HP: -myc oncogene amplification in ductal carcinoma in situ of the breast. Breast Cancer Res Treat 2002, 74(1):25-31.

41. Schlotter CM, Vogt U, Bosse U, Mersch B, Wassmann K: C-myc, not HER-2/ neu, can predict recurrence and mortality of patients with nodenegative breast cancer. Breast Cancer Research 2003, 5(2):R30-6.

42. Pich A, Margaria E, Chiusa L: Oncogenes and Male Breast Carcinomas: CerbB-2 and p53 coexpression predicts a poor Survival. Journal of Clinical Oncology 2000, 18(16):2948-2956.

43. Locker AP, Birrell K, Bell JA, Nicholson RI, Elston CW, Blamey RW, Ellis IO: Ki67 immunoreactivity in breast carcinoma: relationships to prognostic variables and short term survival. European Journal of Surgical Oncology 1992, 18(3):224-9.

44. von Minckwitz G, Sinn HP, Raab G, Loibl S, Blohmer JU, Eidtmann H, Hilfrich J, Merkle E, Jackisch C, Costa SD, Caputo A, Kaufmann M, German Breast Group: Clinical Response After Two Cycles Compared to HER2, Ki67, p53, and bcl-2 in Independently Predicting a Pathological Complete Response After Preoperative Chemotherapy in Patients With Operable Carcinoma of the Breast. Breast Cancer Research 2008, 10(2):R30-41.

45. Wang-Rodriguez J, Cross K, Gallagher S, Djahanban M, Armstrong JM, Wiedner N, Shapiro DH: Male Breast Carcinoma: Correlation of ER, PR, Ki67, Her2-Neu, and p53 with Treatment and Survival, a Study of 65 Cases. Modern Pathology 2002, 15(8):853-861.

46. McClelland RA, Gee JM, O'Sullivan L, Barnes DM, Robertson JF, Ellis IO, Nicholson Rl: p21(WAF1) expression and endocrine response in breast cancer. Journal of Pathology 1999, 188(2):126-32.

47. Curigliano G, Colleoni M, Renne G, Mazzarol G, Gennari R, Peruzzotti G, de Braud E, Robertson C, Maiorano E, Veronesi P, Nolè F, Mandalà M, Ferretti G, Viale G, Goldhirsch A: Recognizing features that are dissimilar in male and female breast cancer: expression of p21Wafl and p27Kip1 using an immunohistochemical assay. Annals of Oncology 2002, 13(6):895-902.

48. Ceccarelli C, Santini D, Chieco P, Lanciotti C, Taffurelli M, Paladini G, Marrano D: Quantitative p21(waf1)/p53 immunohistochemical analysis defines groups of primary invasive breast carcinomas with different prognostic indicators. International Journal of Cancer 2001, 95(2):128-34.

49. André S, Pinto AE, Laranjeira C, Quaresma M, Soares J: Male and Female Breast Cancer-Differences in DNA Ploidy p21and p53 Expression Reinforce the Possibility of Distinct Pathways of Oncogenesis. Pathobiology 2007, 74(6):323-327.

50. Delnnocentes P, Agarwal P, Bird RC: Phenotype-Rescue of CyclinDependent Kinase Inhibitor p16/INK4A Defects in a Spontaneous Canine Cell Model of Breast Cancer. Journal of Cellular Biochemistry 2009, 106(3):491-505.

51. Miranda-Carboni GA, Krum SA, Yee K, Nava M, Deng QE, Pervin S, ColladoHidalgo A, Galic Z, Zack JA, Nakayama K, Nakayama KI, Lane TF: A
Functional Link Between Wnt Signaling and SKP2-Independent p27 Turnover in Mammary Tumors. Genes \& Development 2008, 22(22):3121-3134.

52. Ito $Y$, Kobayashi T, Takeda T, Nakano $Y$, Tamaki $Y$, Komoike $Y$, Wakasugi $E$, Shin E, Takatsuka Y, Kikkawa N, Matsuura N, Monden M: Expression of p16 and Cyclin- dependent kinase 4 proteins in primary breast carcinomas. Oncology 1997, 54(6):508-15.

53. Milde-Langosch K, Bamberger AM, Rieck G, Kelp B, Loning T: Overexpression of the p16 Cell Cycle Inhibitor in Breast Cancer is Associated with a More Malignant Phenotype. Breast Cancer Research and Treatment 2001, 67(1):61-70.

54. Geradts J, Wilson PA: High frequency of abberant p16(Ink4a) expression in human breast cancer. American Journal of Pathology 1996, 149(1):15-20.

55. D’Amico M, Wu K, Di Vizio D, Reutens AT, Stahl M, Fu M, Albanese C, Russell RG, Muller WJ, White M, Negassa A, Lee HW, DePinho RA, Pestell RG: The role of Ink4a/Arf in ErbB2 mammary gland tumorigenesis. Cancer Research 2003, 63(12):3395-402.

doi:10.1186/1477-7819-8-10

Cite this article as: Kanthan et al:: Expression of cell cycle proteins in male breast carcinoma. World Journal of Surgical Oncology 2010 8:10.

\section{Submit your next manuscript to BioMed Central and take full advantage of:}

- Convenient online submission

- Thorough peer review

- No space constraints or color figure charges

- Immediate publication on acceptance

- Inclusion in PubMed, CAS, Scopus and Google Scholar

- Research which is freely available for redistribution
C Biomed Central 